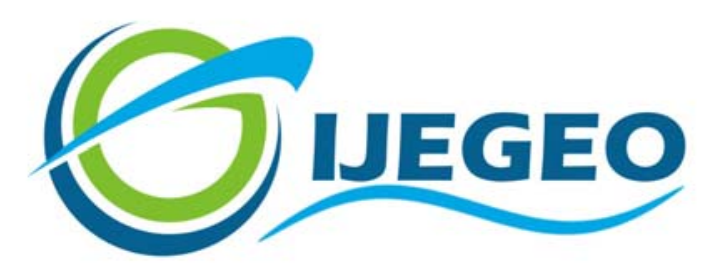

International Journal of Environment and Geoinformatics (IJEGEO) is an international, multidisciplinary, peer reviewed and open access journal.

\title{
Analysis of Different Interpolation Methods for Soil Moisture Mapping Using Field Measurements and Remotely Sensed Data
}

\author{
Mehmet Zeki İmamoğlu and Elif Sertel
}

\section{Editors}

Prof. Dr. Cem Gazioğlu, Prof. Dr. Dursun Zafer Şeker, Prof. Dr. Ayşegül Tanık, Assoc. Prof. Dr. Şinasi Kaya

\section{Scientific Committee}

Assoc. Prof. Dr. Hasan Abdullah (BL), Assist. Prof. Dr. Alias Abdulrahman (MAL), Assist. Prof. Dr. Abdullah Aksu, (TR); Assist. Prof. Dr. Sinan S. Arkın (TR), Prof. Dr. Hasan Atar (TR), Prof. Dr. Lale Balas (TR), Prof. Dr. Levent Bat (TR), Assoc. Prof. Dr. Füsun Balık Şanlı (TR), Prof. Dr. Nuray Balkıs Çağlar (TR), Prof. Dr. Bülent Bayram (TR), Prof. Dr. Şükrü Turan Beşiktepe (TR), Prof. Dr. Selmin Burak (TR), Assoc. Prof. Dr. Gürcan Büyüksalih (TR), Dr. Jadunandan Dash (UK), Assist. Prof. Dr. Volkan Demir (TR), Assoc. Prof. Dr. Hande Demirel (TR), Assoc. Prof. Dr. Nazlı Demirel (TR), Dr. Arta Dilo (NL), Prof. Dr. A. Evren Erginal (TR), Assoc. Prof. Dr. Murat Gündüz (TR), Assoc. Prof. Dr. Kensuke Kawamura (JAPAN), Prof. Dr. Fatmagül Kılıç (TR), Prof. Dr. Ufuk Kocabaş (TR), Prof. Dr. Yusuf Kurucu (TR), Prof. Dr. Hakan Kutoğlu (TR), Prof. Dr. Nebiye Musaoğlu (TR), Prof. Dr. Erhan Mutlu (TR), Assist. Prof. Dr. Hakan Öniz (TR), Assoc. Prof. Dr. Hasan Özdemir (TR), Assoc. Prof. Dr. Barış Salihoğlu (TR), Prof. Dr. Elif Sertel (TR), Prof. Dr. Kadir Seyhan (TR), Prof. Dr. Murat Sezgin (TR), Prof. Dr. Nüket Sivri (TR), Assoc. Prof. Dr. Uğur Şanlı (TR), Assoc. Prof. Dr. Seyfettin Taş (TR), Assoc. Prof. Dr. İ. Noyan Yılmaz (TR), Assist. Prof. Dr. Baki Yokeş (TR), Assist. Prof. Dr. Sibel Zeki (TR), Dr. Hakan Kaya (TR). 


\title{
Analysis of Different Interpolation Methods for Soil Moisture Mapping
}

\section{Using Field Measurements and Remotely Sensed Data}

\author{
Mehmet Zeki İmamoğlu ${ }^{1, *}$ and Elif Sertel ${ }^{2}$ \\ ${ }^{1}$ Istanbul Technical University, Science and Technology Institute, Geomatics Engineering Programme, Maslak, İstanbul. \\ ${ }^{2}$ Istanbul Technical University, Civil Engineering Faculty, Geomatics Engineering Department, Maslak, İstanbul.
}

\begin{abstract}
In this research, we comparatively analyzed different interpolation methods to create soil moisture maps by using field measurements and remotely sensed data. Impacts of number and distribution of field measurements on interpolation procedure was also investigated. Soil moisture measurements of 36 different locations collected from Büyükçekmece water basin and RADARSAT-1 image of the same region obtained simultaneously on 2nd of September 2010 to create soil moisture maps of the study region. Locations of 36 field measurement points were selected considering land use/cover, soil type, elevation, spatial distribution and accessibility to transportation lines. 25 of sample points were used as Control Points (CPs) and used for soil moisture map creation and 11 of them were reserved and used as Independent Check Points (ICPs) to validate the accuracy of each approach applied. Two different experiments were conducted with 25 and 15 CPs to analyze the impact of number and spatial distribution on interpolation. Inverse Distance Weighting (IDW), Global Polynominal Interpolation (GPI), Local Polynominal Interpolation (LPI), Radial Basis Functions (RBF), Kriging, Cokriging and regeression methods were applied to different combination of data sets to create soil moisture maps and obtained results were compared.
\end{abstract}

Keywords: Geoistatistic, GIS, Interpolation, Radarsat-1, Soil Moisture

\section{Introduction}

Anthropogenic changes and pressures occurring on the land surface and water resources have been resulted in degradation of soil structures, water resources and atmospheric composition. Soil moisture is an important parameter affecting energy exchanges between land surface and atmosphere therefore it is attributed as a key variable by the international scientific era to characterize the global climate. Having information on soil moisture is essential for several applications such as prediction of drought and flood conditions, numerical weather forecasting, climate modeling, hydrologic modeling and agronomy (IPCC, 2013; Gazioğlu et al., 2010; Seneviratne et al., 2010; Brocca et al., 2012; Simav et al. 2013;
Laiolo et al., 2015; Panegrossi et al., 2009; Musaoğlu et al., 2002; Alpar et al., 1997).

Soil moisture has a crucial impact on regional and continental water cycle since the amount of soil moisture is strongly influencing the distribution of precipitation between surface runoff, infiltration and percolation which in turn triggers several hydrological and geomorphologic processes. Accurate extraction of soil moisture information is out most important for variety of applications including hydrology, meteorology, climate, agriculture and environment (Laiolo et al., 2015; Baghdadi et al., 2007).

Soil moisture varies with space, time, soil type and texture and it is strongly related with the geographic location, geological structure, topography, land cover and climate (Beven et 
al., 1996). Therefore, it is necessary to investigate spatio-temporal distribution of soil moisture using different technologies. Soil moisture is also crucial for agricultural activities since it impacts the amount of evapotranspiration and groundwater. Extreme soil moisture conditions with huge or scarce amount of moisture can resulted in flood events or indicate droughts, respectively. Water holding capacity of the soil is also effecting the available soil moisture of a given region (IPCC, 2013; Western and Blöschl, 1999). Moreover, global warming is impacting frequency and magnitude of drought events which in turn effect the amount of moisture within the soil as a result of decreased precipitation and evapotranspiration (IPCC, 2013). This decrease in soil moisture has important negative effects on vegetation, water resources and water basins. In order to comprehensively understand these negative impacts and minimize them, soil moisture of different geographic regions (such as water basins, agricultural areas, vegetated areas etc) should be monitored periodically.

Although in-situ methods are extensively used for point-based soil moisture measurements, remote sensing data and methods are fundamental asset for soil moisture studies to derive rapid and economic soil moisture information for larger scales and to analyze its spatial distribution on time. There are several research in literature regarding to use of active and passive remotely sensed data to derive soil moisture information using regression analysis and interpolation approaches (Gevaerta et al., 2016; Zawadzki and Edzior, 2016; Wang et al., 2016; Mozos et al., 2006).

ERS.2 SAR and LANDSAT TM images were used to analyze the results of the heavy flood in Poland in 1997 specifically on settlements and agricultural areas. Integration of LANDSAT thermal band with in situ temperature measurements provided information on the detection of soil moisture on barren lands (Hejmenowska and Mularz, 2000).

Active Synthetic Aperture Radar (SAR) systems are also widely used for the detection of soil moisture; however, there are some limitations corresponding to the wavelength of the SAR system. Although there are several Cband SAR systems available, it is sometimes difficult to derive soil moisture information especially over densely vegetated areas. L-band SAR systems with their longer wavelength have better penetration capacity which facilitates the producing of soil moisture with vegetation (Baghdadi et al., 2007; Şeker et al., 2013). This research is based on C-band RADARSAT-1 data due to the availibity of this data over the region for the studied time and to provide some insight of usage C-band data over a complex landscape then outputs could also feed similar wavelength SAR system such as RADARSAT2, SENTINEL-1 which is free of charge for the scientific community.

It is important to relate satellite based thermal and/or backscaterring measurements with insitu soil moisture data to create soil moisture studies. Regression analysis is one of the widely used method to create this relationship. Moreover, interpolation methods are used to create areal soil moisture maps from pointbased in situ soil moisture measurements. There are mainly two approaches for interpolation; deterministic and geostatistical. Deterministic methods use the extent of similarity within the measured data to create surface information from measured point locations. On the other hand geostatistics use spatial correlation among the measured points to accurately consider spatial characteristics of measured locations (Matheron, 1963).

Inverse distance weighting is the simplest interpolation method. A neighborhood about the interpolated point is identified and a weighted average is taken of the observation values within this neighborhood. Global polynomial interpolation fits a smooth surface that is defined by a mathematical function (a polynomial) to the input sample points. The global polynomial surface changes gradually and captures coarse-scale pattern in the data. Local polynomial interpolation is not an exact interpolator (that is, the surface is a best fit to the data, but does not pass through all the data points). It produces a smooth surface and is best suited to data that exhibits short-range (local) 
variation. Radial basis functions are means to approximate multivariable (also called multivariate) functions by linear combinations of terms based on a single univariate function (the radial basis function). Kriging is a widely used method in geostatistical interpolation. Cokriging considers for a second variable to make better predictions (Matheron, 1963; Olea, 1982).

Geostatistical approach was applied to in situ measurements collected from 42 different locations inside the Büyükçekmece basin which is one of the largest drinking water basins of Istanbul metropolitan city. Soil texture, lime content, $\mathrm{pH}$ and soil salinity thematic maps were created using kriging interpolation technique and then these maps were integrated into the GIS to conduct further spatial analyses (Imamoglu et al., 2011).

In this research, we used soil moisture measurements of 35 different locations collected from Büyükçekmece basin and RADARSAT-1 image of the same region obtained simultaneously on $2^{\text {nd }}$ September 2010 to create soil moisture maps of the study region. We applied both geostatistical and deterministic interpolation techniques to both in-situ and SAR data to compare results of different approaches to better derivation of soil moisture information for unknown locations. Kriging, Inverse Distance Weighting (IDW), Global Polynominal Interpolation (GPI), Local Polynominal Interpolation (LPI), Radial Basis Functions (RBF) methods were applied to field measurements, regression analysis was applied to integrate SAR and field measurements and co-kriging method was applied to SAR and field measured soil moisture dat. Moreover, as a second step, number and distribution of Control Points (CPs)-points used in interpolation-were changed to analyze the impact of number and distribution of sample points on different methods to create soil moisture maps. In addition to Root Mean Square Error (RMSE) of Control Points (CPs), Identical 11 Check Points (ICPs), independent from these CPs were also used to objectively validate the accuracy of different methods. This research includes comprehensive analysis of different interpolation methods applied to insitu and SAR data to comparatively illustrate the most convenient approaches for soil moisture mapping.

\section{Study Area}

Istanbul is one of the world's most ancient cities. Founded on the Strait of Istanbul (Bosphours) and linking Asia to Europe, it is also Turkey's biggest city in terms of history, trade, population and culture and for centuries was the capital of the Byzantine and Ottomon empires (Algan et al., 2011).

The study area is located in the long distance protection zone of Büyükçekmece Basin which is one of the biggest drinking water basins in Istanbul and also includes some parts of Catalca and Silivri counties (Kaya and Gazioğlu, 2015). The study area mainly consists of agricultural land but it also contains some urban, mining and forest cover areas to a certain extent. Location of the study area and in situ measurement points of soil samples are shown in Figure 1.

\section{Material}

In this research, pan sharpened IKONOS imagery with 1 meter spatial resolution, Radarsat-1 imagery, Digital Elevation model derived from 1/5000 scale topographical maps and soil maps produced by Ministry of Agriculture are used as main geographic data. In addition, a field measurement campaign was conducted simultaneously with RADARSAT-1 image acquisition time on 2nd Of September, 2016. Geometric correction was used to eliminate errors in the images in a common coordinate system (Sertel et al., 2007). 36 different soil sample locations were selected to represent different land use categories, elevation values and soil types, as well as considering transportation options to easily access alternative measurement locations. Coordinates of these 36 soil sample points were determined by GPS measurements. In order to be able to relate soil moisture with RADAR backscattering in the further stages of the research, soil samples were collected from top $15 \mathrm{~cm}$ of land surface using long metal cylinders. Soil samples were analyzed for lime content, structure, salt content, soil reaction 
$(\mathrm{pH})$, soil moisture, carbon and nitrogen. In this study, soil moisture analyses are presented.

Radarsat-1 is Canada's first civilian SAR satellite and it was launched from Vandeeberg Airforce Base, California on 4 November 1995. SAR satellites are active system capable of collecting images in variety of weather conditions during day and night. It has different beam modes with different beam widths and its beam width coverage changes from $50 \mathrm{~km}$ to $500 \mathrm{~km}$ depending on the mode. Radarsat- 1 is a C-band SAR system similar to RADARSAT-2, upcoming RASARSAT constellation and European Sentinel-1 satellites.

A spatial database including geographic location of 36 sample points and attributes obtained from the laboratory analysis such as soil moisture amount, lime content, $\mathrm{PH}$ value was created for further analysis. In order to generate spatial information for the whole study area, different interpolation techniques were used and surface areal soil moisture maps were produced which are not representing information only for the measured locations but also for the unknown locations. Different interpolation methods namely Kriging, Kokriging, Regression, IDW, GPI, LPI and RBF were applied to SAR and/or field measurement data to conduct a comprehensive and comparative investigation of different interpolation methods to create accurate soil moisture maps. Measured field data was split into two groups namely Control Points (CPs) used in interpolation and/or modeling and some of the points were reserved but not used in interpolation procedure which are called Independent Check Points (ICPs) to objectively analyze the accuracy of different methods. There are 25 CPs and 11 ICPs used in the further analysis of different approaches.

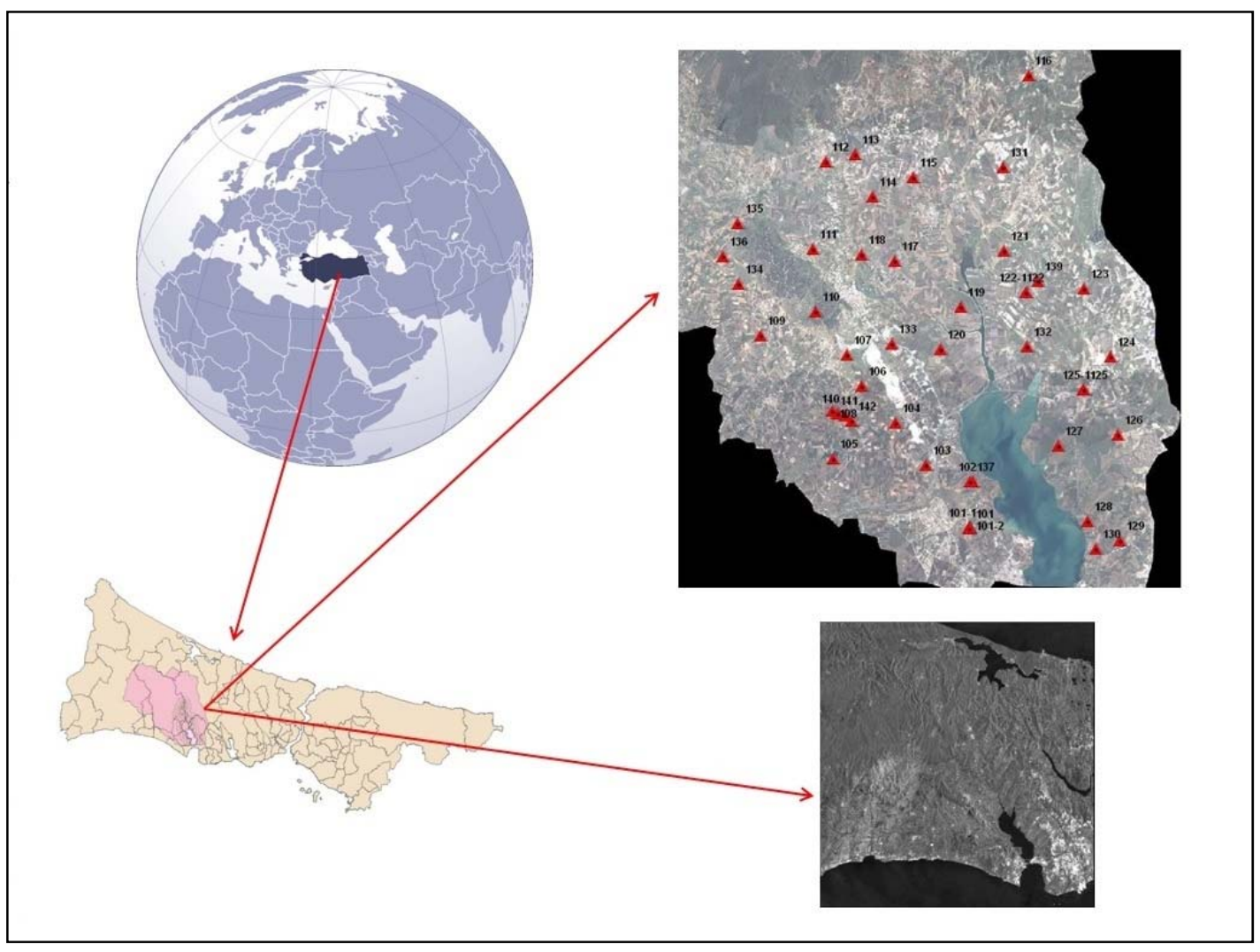

Figure 1. Study Area and Location of Sample Points 


\section{Methodology}

\section{Radar Image Processing}

Radarsat-1 image was rectified using Ground Control Points(GCPs) obtained from orthorectified IKONOS imagery of the same region. Different filters were applied to SAR image to suppress the noise effects. Betanought values for every pixel were calculated from back scattered data before relating SAR data and field measurements.

\section{Regression Analysis}

Regression analysis was conducted to relate SAR backscattered data with field measurements. In this research, regression analysis with 25 control points with an equation of $y=-1,345 x+2,713$ has the $R^{2}$ value of 0.703 , whereas, regression analysis with 15 control points with an equation of $y=-1,348 x+$ 2,375 has the $\mathrm{R}^{2}$ value of 0.832 .

\section{Interpolation Methods}

Different interpolation and geostatistical techniques were used to create soil moisture map of the study area using point-based field measurements. Firstly, semivariograms were generated using soil moisture value and location of field measurements. Mathematical models like spherical, circular, exponential and Gaussian were fitted to experimental variograms and threshold, range and Nugget variances for each model were examined to find out the best model representing the variograms.

Determination of observed data's experimental variogram structure and forming of theoretical model for its structure are the basis for geostatistical studies (Matheron; 1963; Imamoglu et al.,2011). Regionalized Variable Theory which implements measurements for the spatial dependence of continuous variables, is an important tool in geostatistics and semivariogram is the key in this theory. Variogram represents spatial change of regionalized variables, which are random variables with known location in time and space. Kriging analysis using semivariogram is widely used to estimate parameters in nonsampled locations (Matheron, 1963; Delhomme, 1978; Vieira, 1983).

After the calculation of semivariograms, kriging and co-kriging methods were applied. In addition, deterministic methods of Inverse Distance Weighting (IDW), Global Polynomial Interpolation (GPI), Local Polynomial Interpolation (LPI) and Radial Basis Functions (RBF) were also employed with the aim of producing soil moisture maps.

\section{Inverse Distance Weighting (IDW)}

Inverse distance weighting is a deterministic, nonlinear interpolation technique. For soil moisture mapping, IDW uses a weighted average of the soil moisture values from nearby sample points to estimate the soil moisture values of un-sampled locations. IDW is based on the Tobler's first law of geography referring the similarity of two locations decreases with increasing distance. The simplest model involves dividing each of the observations by the distance it is from the target point raised to a power $\alpha$ (Matheron, 1963; Tobler, 1970).

$Z_{j}=k_{j} \sum_{i=1}^{n} \frac{1}{d_{i j} \alpha} Z_{i}$

The value $k_{j}$ in this expression is an adjustment to ensure that the weights add up to 1 . If the parameter $\alpha=1$ we have:

$$
k_{j}=\sum_{i=1}^{n} \frac{1}{d_{i j}}
$$

\section{Global Polynomial Interpolation} (GPI)

Global Polynomial (GP) is a quick and inexact deterministic interpolator. GP methods give better results for slowly and gradually changing 
surfaces. The impacts of the locations toward the edge of the data are higher (Vieira, 1983; Tobler, 1970). There are very few decisions to make regarding model parameters. It is best used for surfaces that change slowly and gradually. However, there is no assessment of prediction errors and it may be too smooth. Locations at the edge of the data can have a large effect on the surface. There are no assumptions required of the data (URL 1). A polynomial that goes through a set number $(\mathrm{m}+1)$ of points. A global polynomial is defined over the entire region of space

$p_{m}(x)=\sum_{i=0}^{m} c_{j} x^{j}$

This polynomial is of degree $\mathrm{m}$ (highest power is $\left.\mathrm{x}^{\mathrm{m}}\right)$ and order $\mathrm{m}+1\left(\mathrm{~m}+1\right.$ parameters $\left.\left\{\mathrm{c}_{\mathrm{j}}\right\}\right)$. If we are given a set of $m+1$ points.

$y_{1}=f_{(x 1)}, y_{2}=f_{(x 2)}, \ldots y_{m+1}=f_{\left(x_{m+1}\right)}$

\section{Local Polynomial Interpolation (LPI)}

LPI is the integration of GP and the moving average procedure. In LPI, $1^{\text {st }}, 2^{\text {nd }}$ or $3^{\text {rd }}$ order GP is fitted to local subset of entire data set defined by a window similar to the moving average approach. In order to include sufficient number of data points to the process, the window size should be large. An adjusted version of least squares model by introducing a measure of distance-based weighting called weighted least squares is used in this method for fitting. A power function of distance as a fraction of the window size is used for the calculation of weights. The simplest case of LPI is to apply a circle with redius of $R$ as the moving window. In the below equation, $d_{i}$ denotes the distance between grid point $\left(x_{i}, y_{i}\right)$ and a data point $(x, y)$ within the circle an the weight $w_{i}$ is defined as (Smith et al., 2007).

$w_{i}=\left(1-\frac{d_{i}}{R}\right)^{P}$ where $p$ is a user definable power. The least squares procedure then involves minimizing the expression:

$\sum_{i=1}^{n} w_{i}\left(f\left(x_{i}, y_{i}\right)-z_{i}\right)^{2}$

If $p=0$ all the weights are 1 .

\section{Radial Basis Functions (RBF)}

The RBF method is a common approach to interpolate multidimensional scattered data because of being simple and accurately approximating an underlying function (Grady, 2003; Baxter, 1992).

A radial basis function approximation takes the form,

$s(x)=\sum_{i \in 1}^{n} y_{i} \varphi(\|x-i\|), \quad x \in R^{d}$,

Where $\varphi:[0, \infty) \rightarrow \mathrm{R}$ is a fixed univariate function and the coefficients $\left(\mathrm{y}_{\mathrm{i}}\right)_{\mathrm{i} \in I_{I} \text { are real }}$ numbers.

\section{Kriging}

Kriging interpolation method estimates values in points with no ground measurements by using variogram structure characteristics of ground samples which are in close proximity with each other. Most important characteristic and advantage of Kriging that separates this method from other interpolation techniques is that there are variance values for the estimation of each and every area or point. This gives information about the confidence degree of the estimated/predicted value (Matheron, 1963; Delhomme, 1978; Sertel et al., 2012).

$Z\left(s_{0}\right)=\sum_{i=1}^{N} \lambda_{i} Z\left(S_{i}\right)$

where: 
$Z\left(s_{i}\right)=$ the measured value at the $i$ th location, $\lambda_{i}$ $=$ an un1978known weight for the measured value at the $i$ th location, $s_{0}=$ the prediction location, $N=$ the number of measured values.

\section{Cokriging:}

Cokriging is a variation of the ordinary kriging which takes into account a secondary variable having relationship with the main variable that you want to estimate. This method minimizes the variance of the estimation error by exploiting the cross-correlation between two variables. Cross-correlated information contained in the secondary variable resulted in decrease of the variance of the estimation errors. Application of cokriging is useful if the primary variable of interest is under sampled and secondary variable is more denser to provide the cross correlated information (Laurent et al., 2013; Xiaoqing et al., 2013). Soil moisture is used as primary variable due to the limited number of field measurements and SAR backscattering which includes the signal of soil moisture and much more denser considering the size and spatial resolution of SAR image is used as secondary variable in our research.

The Cokriging estimation model can be summarized as follows:

$Z\left(x_{0}\right)=\sum_{i=1}^{n} \omega_{1 i} Z_{1}\left(x_{i}\right)+\sum_{i=1}^{p} \omega_{2 j} Z_{2}\left(x_{j}\right)(9)$

where $Z\left(x_{0}\right)$ is the position of the sample point; $\omega_{1 i}$ and $\omega_{2 j}$ are two regionalized variables; and
$Z_{1}\left(x_{i}\right)$ and $Z_{2}\left(x_{j}\right)$ are weight coefficients (Eldeiry and Garcia, 2010).

In this study; 11 points, which approximately correspond to $\% 20$ of 36 sample points are chosen as ICPs to to check the accuracy of each method applied. At the first experiment, $25 \mathrm{CPs}$ were used for different interpolation approaches and RMSE values were obtained for each model and then RMSE of 11 CPs were also analyzed to illustrate the accuracy of each mode. As a second step, 10 CPs were omitted and another experiment was conducted with remaining $15 \mathrm{CPs}$ to analyze the impact of number and distribution of CPs on different interpolation approaches. Same 11 ICPs were used to analyze the accuracy of the second experiment to be consistent for both data set.

\section{Results and Discussion}

First of all, Radarsat-1 imagery was geometrically corrected then betanought values are calculated by using pixel's reflection values. Regression analysis was performed between this betanouht values and soil moisture values of samples collected from the ground in order to reveal the correlation among them. Figure 2 shows the regression analysis with 25 control points, $\mathrm{R}^{2}$ is found 0.703 in this application. Later, 10 additional control points (homogenously selected) excluded from the model and regression analysis is performed with 15 control points. Figure 3 shows the correlation between Radarsat-1 betaught values and 15 control points. This model's $\mathrm{R}^{2}$ is rises to 0.832 . 


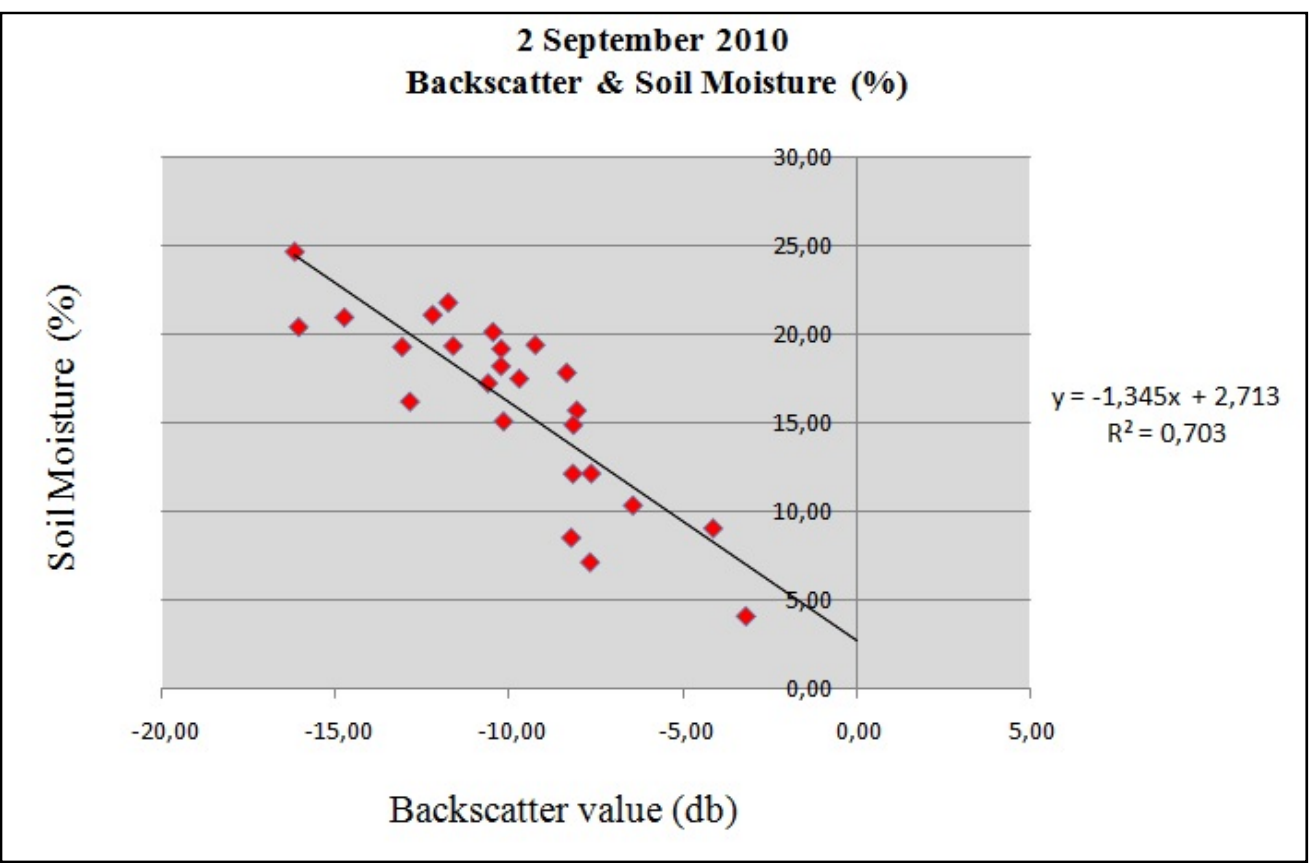

Figure 2. The Correlation Between Radarsat-1 Backscatter Values and Soil Moisture Value of 25 Control Points.

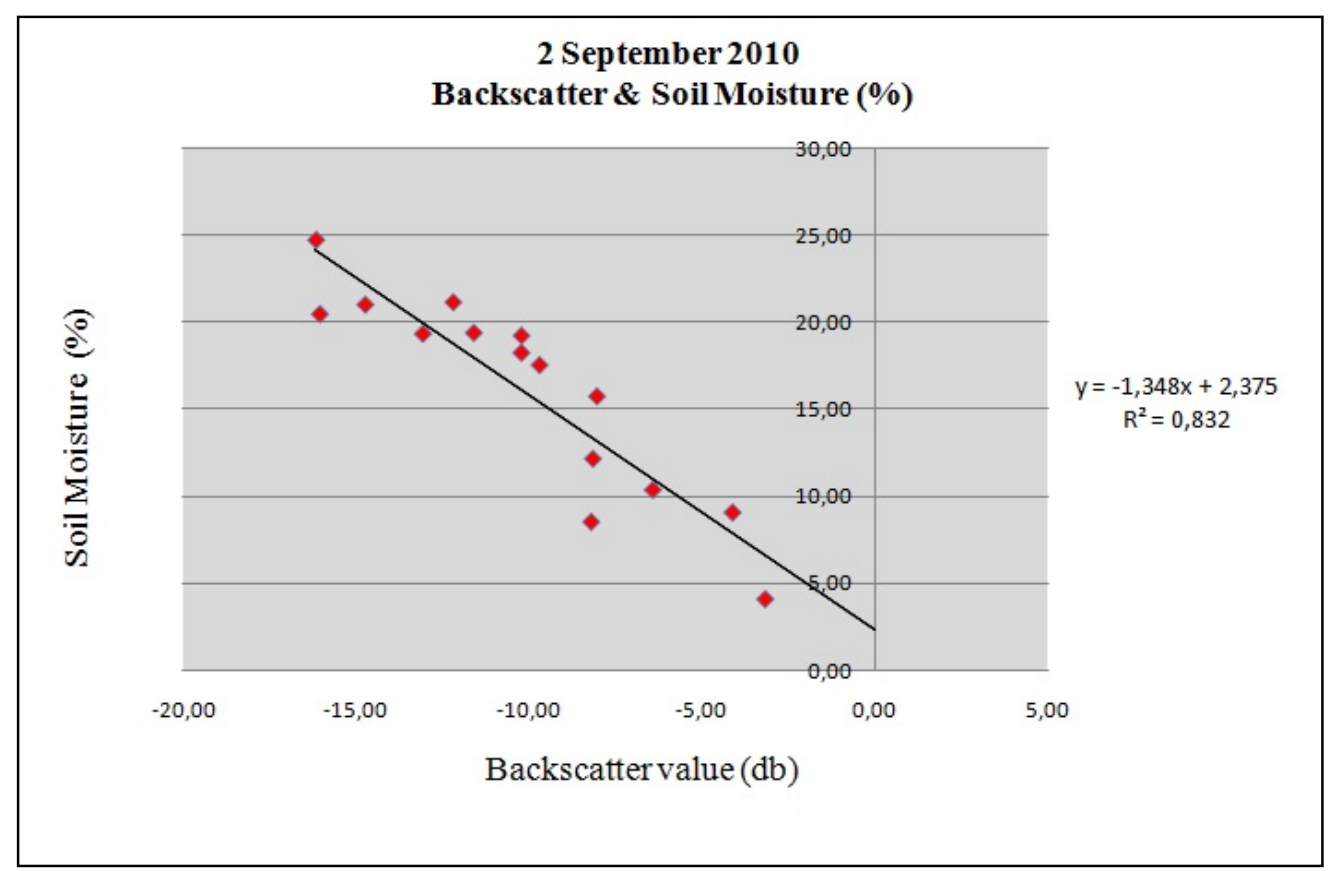

Figure 3. The Correlation Between Radarsat-1 Backscatter Values and Soil Moisture Value of 15 Control Points 
Secondly, 11 points which are roughly $\% 20$ of the ground control points are selected as check points and various analyses are performed using 25 control points. At first, regression analyses and different interpolation techniques are executed with this points. In last stage, 11 check point values are compared with these results with the purpose of finding the best performing analyses. Also, 10 more control points are excluded from these models to find out the effects of the number of control points on results by analyzing remaining 15 points and comparing the results with 11 check points.

Figure 4 presents soil moisture maps interpolated using 25 CPs using Inverse Distance Weighting (IDW), Global Polynominal Interpolation (GPI), Local Polynominal Interpolation (LPI), Radial Basis Functions (RBF), Kiriging and Cokriging methods. A general pattern similarity can be noticed in these maps created with different methods. Furthermore, it is seen that southwest and north east of the maps shows higher soil moisture values while middle regions have less soil moisture.

Figure 5 shows the maps created from 15 control points with different methods, which exhibit great similarity with 25 control point maps. Again, southwest and northeast of the maps shows higher values of soil moisture then the middle regions.

Tables 1-3 are created to summarize and compare the results achieved by different methods. In these tables, the locations of 11 check points, moisture values measured in these locations, land use information, results of different interpolation techniques and the difference of these results are presented.

Table 1 presents the moisture values of 11 check points calculated from 25 control points and the respected techniques used for analyses. Examination of RMS values presented at table 3 in conjunction with ground control soil moisture values and results of the interpolation techniques shows that best performing method is Ordinary Kriging with $\mathrm{RMS}=3,534$. However, individual examination of points shows that other methods have better results in some points. For example, at 1 st check point, IDW has better results. Similarly GPI in 2nd check point, LPI in 3rd check point, Ordinary Kriging in 4 th check point gives better results. Nevertheless, results acquired by Radar data and Cokriging method applied to Radar data have the highest error and lowest performance.

Table 2 shows the soil moisture values of 11 check points obtained from maps created by the interpolation of 15 points with different techniques. Examining the RMS values in table 3 in conjunction with ground sample values and map values shows that best performing result for this model is obtained through Cokriging with $\mathrm{RMS}=3,935$. Similar to the 25 point analysis, at some individual points, other methods gives better results such as RDF for 1st point, GPI for 2 nd point, LPI for 3rd point, Kriging for 8th point and Kokriging for $11^{\text {th }}$ point gives better results.

\section{Conclusions and Further Research}

In this study, soil moisture maps were created using various interpolation techniques and geostatistical methods by means of field soil moisture and SAR image data. Alternative methods have the advantage of being faster in wider study areas over the conventional methods. It is observed that having accurate results with interpolation techniques depend on the frequency of sampling locations. More accurate results could be obtained by increasing the number of control points which are homogenously distributed over the study area. Sampling of the ground truth also affects the accuracy of the border between soil groups. If the physical parameters such as depth of soil, slope of the terrain are taken into consideration, different interpolation and geostatistical methods could give better results. In this study, Inverse Distance Weighting (IDW), Global Polynominal Interpolation (GPI), Local Polynominal Interpolation (LPI), Radial Basis Functions (RBF) interpolation techniques and Kriging, Cokriging geostatistical techniques are compared and Ordinary Kriging is discovered to be the best performer among them 


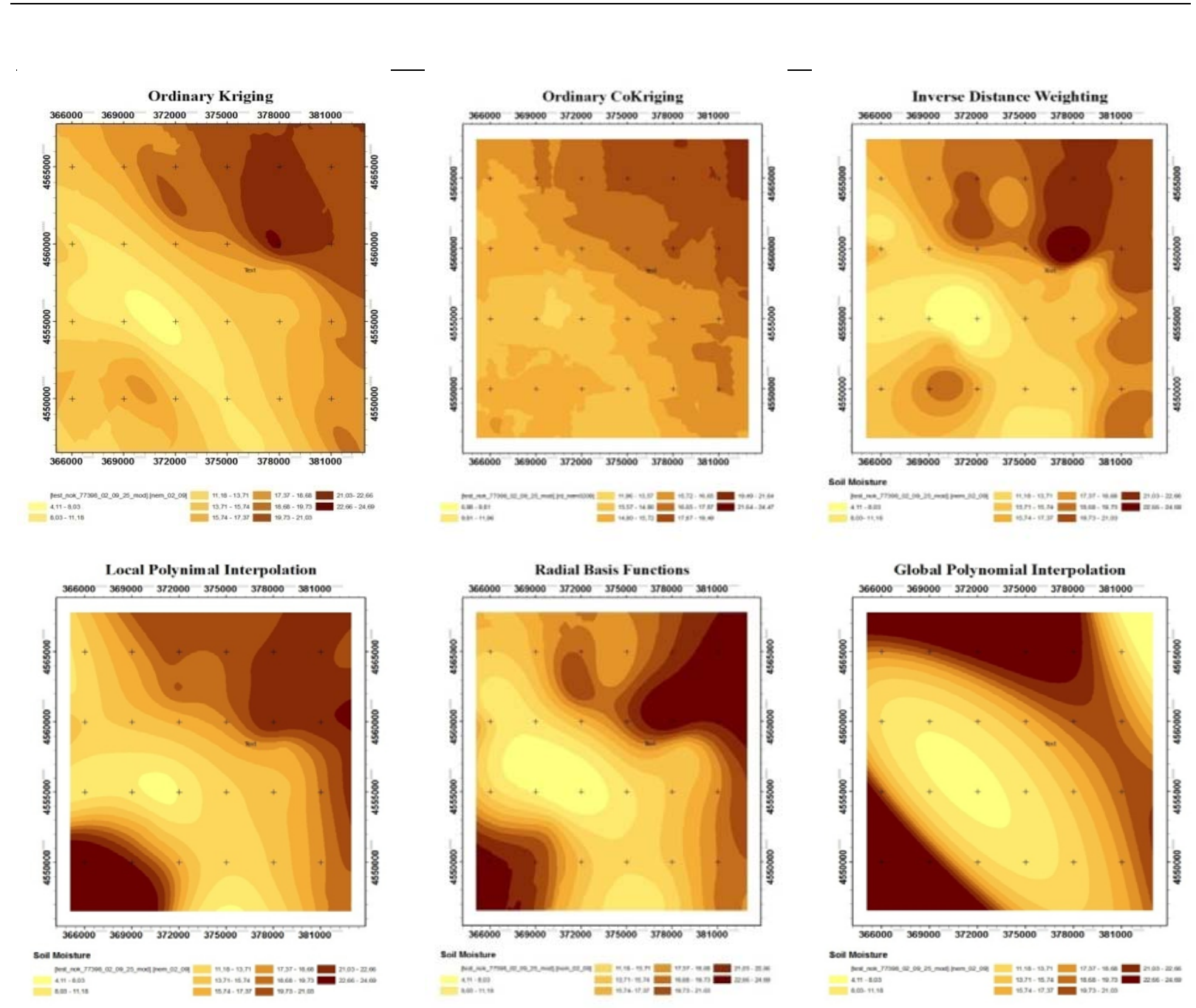

Figure 4. Soil Moisture Maps Calculated From 25 Soil Moisture Value Control Points With Different of Interpolation Techniques 

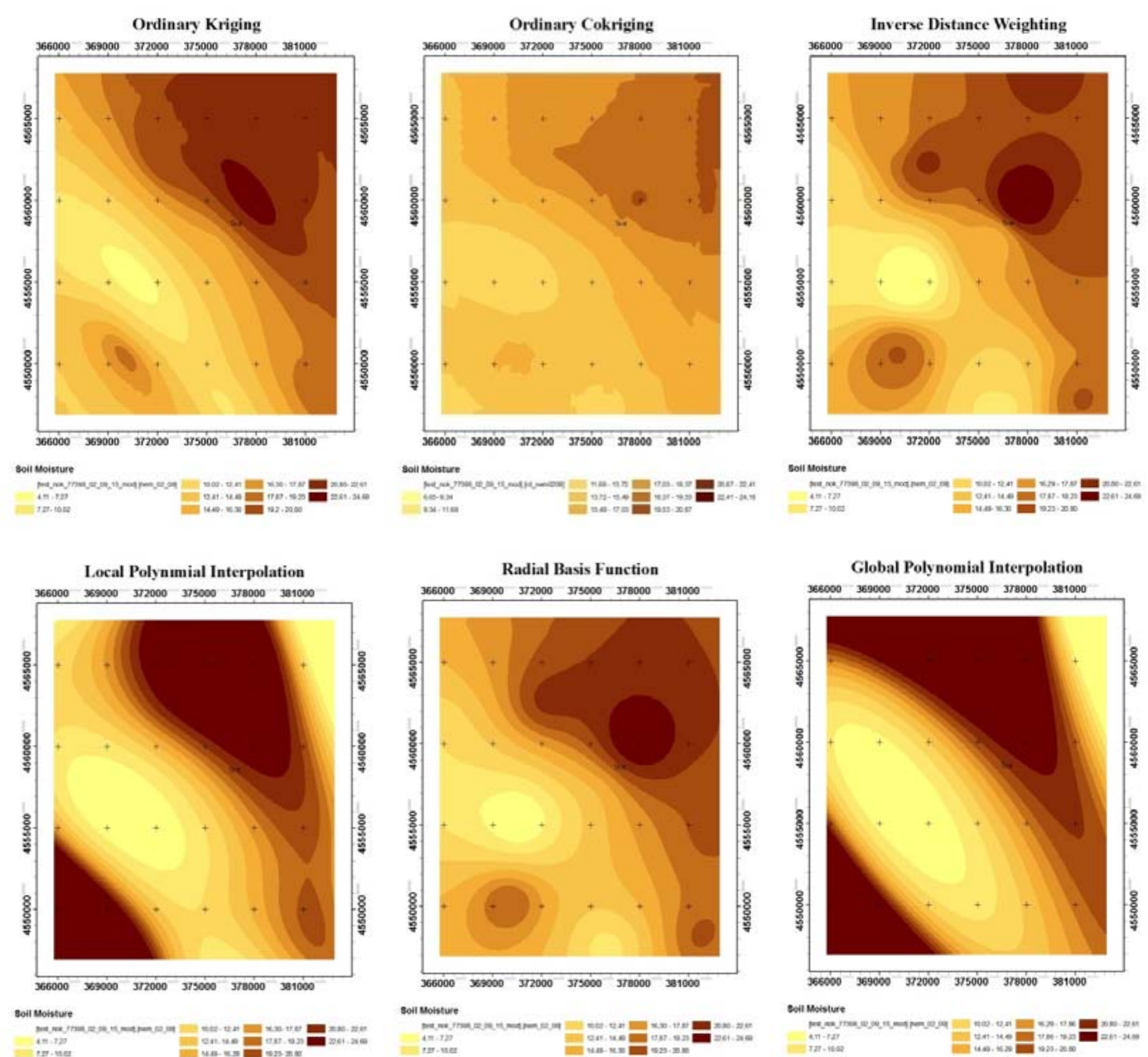

Figure 5. Soil Moisture Maps Calculated From 25 Soil Moisture Value Control Points With Different of Interpolation Techniques 
Table 1. Soil Moisture Values of 11 check points obtained from maps created by the interpolation of 25 Control Points With Different Techniques

\begin{tabular}{|c|c|c|c|c|c|c|c|c|c|c|c|c|c|c|c|c|c|c|}
\hline S.No. & Sample points & $\mathrm{x}$ & y & Measured & Kriging & \begin{tabular}{|l|} 
Measured-Kriging \\
\end{tabular} & Cokriging & \begin{tabular}{|l|} 
Measured-Cokriging \\
\end{tabular} & Radar & \begin{tabular}{|l|} 
Measured-Radar \\
\end{tabular} & IDW & Measured-IDW & GPI_3 & Measured-GPI & LPI & Measured-LPI & RBF & Measured-RBF \\
\hline 1 & $101 / 2$ & 376146,23 & 4547454,43 & 7,99000 & 9,63284 & $-1,64284$ & 13,68590 & $-5,69590$ & 17,71661 & $-9,72661$ & 9,07000 & $-1,08000$ & 12,62410 & $-4,63410$ & 9,24333 & $-1,25333$ & 9,07144 & $-1,08144$ \\
\hline 2 & 103 & 374191,12 & 4550257,45 & 8,54000 & 11,09720 & $-2,55720$ & 14,79320 & $-6,25320$ & 23,56334 & $-15,02334$ & 12,37570 & $-3,83570$ & 9,85620 & $-1,31620$ & 12,39760 & $-3,85760$ & 12,00580 & $-3,46580$ \\
\hline 3 & 104 & 372843,33 & 4552194,738 & 12,53000 & 9,98316 & 2,54684 & 14,53040 & $-2,00040$ & 6,07515 & 6,45485 & 11,15250 & 1,37750 & 8,29683 & 4,23317 & 11,93080 & 0,59920 & 10,83600 & 1,69400 \\
\hline 4 & 110 & 369258,89 & 4557157,38 & 7,84521 & 8,20485 & $-0,35964$ & 13,95250 & $-6,10729$ & 20,36789 & $-12,52268$ & 8,84601 & $-1,00080$ & 7,17290 & 0,67231 & 9,96888 & $-2,12367$ & 5,11640 & 2,72881 \\
\hline 5 & 111 & 369122,92 & 4559992,17 & 8,20641 & 11,98030 & $-3,77389$ & 15,45500 & $-7,24859$ & 14,43001 & $-6,22360$ & 14,77640 & $-6,56999$ & 8,82022 & $-0,61381$ & 14,49940 & $-6,29299$ & 10,42360 & $-2,21719$ \\
\hline 6 & 118 & 371327,87 & 4559720,80 & 11,83602 & 14,63550 & $-2,79948$ & 15,70120 & $-3,86518$ & 19,49514 & $-7,65912$ & 17,31270 & $-5,47668$ & 10,20670 & 1,62932 & 15,36870 & $-3,53268$ & 13,74380 & $-1,90778$ \\
\hline 7 & 124 & 382489,91 & 4555136,34 & 24,40778 & 18,99370 & 5,41408 & 17,48030 & 6,92748 & 12,51518 & 11,89260 & 18,80860 & 5,59918 & 20,56570 & 3,84208 & 21,11410 & 3,29368 & 20,44790 & 3,95988 \\
\hline 8 & 126 & 382829,83 & 4551622,91 & 23,86602 & 18,61920 & 5,24682 & 16,11990 & 7,74612 & 16,14404 & 7,72198 & 18,56320 & 5,30282 & 21,10450 & 2,76152 & 20,61490 & 3,25112 & 20,20750 & 3,65852 \\
\hline 9 & 137 & 376235,86 & 4549542,23 & 9,67291 & 12,02710 & $-2,35419$ & 14,76530 & $-5,09239$ & 16,38947 & $-6,71656$ & 12,15000 & $-2,47709$ & 10,67040 & $-0,99749$ & 12,01750 & $-2,34459$ & 12,12360 & $-2,45069$ \\
\hline 10 & 139 & 365800,60 & 4558418,77 & 18,36267 & 19,36670 & $-1,00403$ & 17,19800 & 1,16467 & 10,89059 & 7,47208 & 15,56250 & 2,80017 & 19,59050 & $-1,22783$ & 18,72190 & $-0,35923$ & 17,31200 & 1,05067 \\
\hline 11 & 140 & 370229,35 & 4552593,38 & 18,39706 & 15,13600 & 3,26106 & 14,87550 & 3,52156 & 13,69858 & 4,69848 & 16,19270 & 2,20436 & 11,26470 & 7,13236 & 14,72180 & 3,67526 & 16,00030 & 2,39676 \\
\hline
\end{tabular}

Table 2. Soil Moisture Values of 11 check points obtained from maps created by the interpolation of 15 Control Points With Different Techniques

\begin{tabular}{|c|c|c|c|c|c|c|c|c|c|c|c|c|c|c|c|c|c|c|}
\hline S.No. & Sample points & $x$ & y & Measured & Kriging & Measured-Kriging & Cokriging & Measured-Cokriging & Radar & Measured-Radar & IDW & Measured-IDW & GPI_3 & Measured-GPI & LPI & Measured-LPI & RBF & Measured-RBF \\
\hline 1 & $101 / 2$ & 376146,23 & 4547454,43 & 7,99000 & 9,07540 & $-1,08540$ & 12,71600 & $-4,72600$ & 17,41207 & $-9,42207$ & 9,07000 & $-1,08000$ & 12,00560 & $-4,01560$ & 9,28135 & $-1,29135$ & 9,07083 & $-1,08083$ \\
\hline 2 & 103 & 374191,12 & 4550257,45 & 8,54000 & 10,45780 & $-1,91780$ & 14,43290 & $-5,89290$ & 23,27185 & $-14,73185$ & 12,64980 & $-4,10980$ & $\begin{array}{ll}8,46468 \\
\end{array}$ & 0,07532 & $\begin{array}{l}, 80965 \\
9\end{array}$ & $-1,26965$ & 13,37000 & $-4,83000$ \\
\hline 3 & 104 & 372843,33 & 4552194,738 & 12,53000 & 9,27309 & 3,25691 & 14,34860 & $-1,81860$ & 5,74465 & 6,78535 & 13,47750 & $-0,94750$ & 6,28980 & 6,24020 & $\begin{array}{ll}7,51949 \\
\end{array}$ & 5,01051 & 13,10640 & $-0,57640$ \\
\hline 4 & 110 & 369258,89 & 4557157,38 & 7,84521 & 7,15905 & 0,68616 & 13,08340 & $-5,23819$ & 20,06927 & $-12,22406$ & $\begin{array}{ll}8,24904 \\
\end{array}$ & $-0,40383$ & $\begin{array}{ll}3,84544 \\
\end{array}$ & 3,99977 & $\begin{array}{ll}4,11298 \\
\end{array}$ & 3,73223 & 7,73605 & 0,10916 \\
\hline 5 & 111 & 369122,92 & 4559992,17 & 8,20641 & 11,81230 & $-3,60589$ & 15,14090 & $-6,93449$ & 14,11816 & $-5,91175$ & 14,31760 & $-6,11119$ & 6,45153 & 1,75488 & $\begin{array}{ll}9,01956 \\
\end{array}$ & $-0,81315$ & 12,82430 & $-4,61789$ \\
\hline 6 & 118 & 371327,87 & 4559720,80 & 11,83602 & 14,68790 & $-2,85188$ & 15,63640 & $-3,80038$ & 19,19457 & $-7,35855$ & 17,00550 & $-5,16948$ & 9,97227 & 1,86375 & 11,80280 & 0,03322 & 15,06230 & $-3,22628$ \\
\hline 7 & 124 & 382489,91 & 4555136,34 & 24,40778 & 19,91410 & 4,49368 & 17,69130 & 6,71648 & 12,19904 & 12,20874 & 19,19270 & 5,21508 & 19,40520 & 5,00258 & 18,37800 & 6,02978 & 19,53550 & 4,87228 \\
\hline 8 & 126 & 382829,83 & 4551622,91 & 23,86602 & 18,53250 & 5,33352 & 16,91340 & 6,95262 & 15,83600 & 8,03002 & 18,53220 & 5,33382 & 20,17240 & 3,69362 & 17,72640 & 6,13962 & 18,92300 & 4,94302 \\
\hline 9 & 137 & 376235,86 & 4549542,23 & 9,67291 & 12,06520 & $-2,39229$ & 14,36700 & $-4,69409$ & 16,08198 & $-6,40907$ & 12,14990 & $-2,47699$ & 10,22330 & $-0,55039$ & 11,68140 & $-2,00849$ & 12,16310 & $-2,49019$ \\
\hline 10 & 139 & 365800,60 & 4558418,77 & 18,36267 & 22,45160 & $-4,08893$ & 18,74120 & $-0,37853$ & 10,57083 & 7,79184 & 21,53490 & $-3,17223$ & 22,99910 & $-4,63643$ & 23,06170 & $-4,69903$ & 21,97670 & -3,61403 \\
\hline 11 & 140 & 370229,35 & 4552593,38 & 18,39706 & 11,99450 & 6,40256 & 14,16640 & 4,23066 & 13,38508 & 5,01198 & 14,18400 & 4,21306 & 8,81526 & 9,58180 & 9,86406 & 8,53300 & 12,89700 & 5,50006 \\
\hline
\end{tabular}


Table 3. RMS Values Crated by 25 and 15 Control Points With different Techniques

\begin{tabular}{|c|c|c|}
\hline \multirow{2}{*}{ Methods } & 25 Points & 15 Points \\
\cline { 2 - 3 } & RMS & RMS \\
\hline Kriging & 3,53400 & 4,25000 \\
\hline Cokriging & 3,59600 & 3,93500 \\
\hline IDW & 3,80200 & 4,75800 \\
\hline GPI & 4,65200 & 5,98100 \\
\hline LPI & 3,69400 & \\
\hline RBF & 3,70500 & 4,66900 \\
\hline
\end{tabular}

But, other techniques did give better results in some individual points. However, RMS error matrices of mentioned techniques revealed that the lowest RMS error is acquired by Ordinary Kriging in 25 point model, Cokriging in 15 point model. Inspection of Table 1 and Table 2 shows that higher control points yield optimum results and lower RMS values. IDW, RBF and LPI methods produce similar results wiith ordinary kriging.

SAR-based results produce comperatively coearser RMSE values compared to other interpolation methods due to the impact on Cband on soil moisture. On land cover classes having barren land and sparse vegetation SAR data provides good results wehereas on densely vegetated ares C-band SAR fails to simulate soil moisture precisely. Moreover, it is importnat to emphasize the betetr results obtained with co-kriging compared to regresiion while creating soil moistore maps from SAR images in conjuction with field soil moisture measurement.

Our results show the importance of ICPs usage for validation of diiffernt approach. In some cases, althous RMSE of CPs used to fit model produce reasonable results, validation of these results with ICPs which were not used in modeling procedure illustrates that RMSE value can vary.

\section{Acknowledgements}

The authors would like to thank Istanbul University for laboratory analysis, Istanbul
Technical University-Center of Satellite Communication and Remote Sensing (ITUCSCRS) for RADRSAT-1 image support, Istanbul Metropolitan Municipality for providing some spatial data used in the research and Ms. Irmak YAY ALGAN for her kind contributions

\section{References}

Algan, O., Yalçın, M.N., Özdoğan, M., Yılmaz, Y., Sarı, E., Kırc1-Elmas, E., Yılmaz,İ., Bulkan,Ö., Ongan, D., Gazioğlu, C., Nazik, A., Polat, M.A., and Meriç, E. (2011). Holocene coastal change in the ancient harbor of Yenikapi-İstanbul and its impact on cultural history. Quaternary Research, Vol .76 (1), pp.30-45.

Alpar, B., Burak, S. and Gazioğlu, C. (1997). Effect of weather system on the regime of sea level variations in İzmir Bay, Turkish Journal of Marine Sciences, 3 (1997), pp. 83-92

Alvarez-Mozos,J., Casalí, J., GonzálezAudícana, M., Verhoest N. E. C., 2006. Assessment of the Operational Applicability of RADARSAT-1 Data for Surface Soil Moisture Estimation. IEEE Transactions on Geoscience and Remote Sensing 44, 913924.

Baghdadi, N. Aubert, M. Cerdan, O., Franchistéguy, L., Viel, C., Martin, E., Zribi, M., Desprats, J.F. 2007. Operational Mapping of Soil Moisture Using Synthetic Aperture Radar Data: Application to the Touch Basin (France), Sensor.

Baxter, B. J.C. 1992. The Interpolation Theory Of Radial Basis Functions. 
Beven, K.J.; Fisher, J. 1996. Remote sensing and scaling in hydrology. In Scaling up hydrology using remote sensing; Stewart, J.B., Engman, E.T., Fedes, R.A., Kerr, Y., Eds.; Wiley Press: Chichester, UK.

Brocca, L., Moramarco, T., Melone, F., Wagner, W., Hasenauer, S., Hahn, S., 2012. Assimilation of surface- and root-zone ASCAT soil moisture products intorainfall-runoff modeling. IEEE Trans. Geosci. Remote Sens., 2542-2555.

Delhomme, J.P.,1978. Kriging in the Hydrosciences, Advances in Water Resources, 5, 251-266.

Eldeiry AA, Garcia LA 2010. Comparison of ordinary kriging, regression kriging, and cokriging techniques to estimate soil salinity using LANDSAT images. J.Irrig Drain ASCE 136: 355-364.

Gazioğlu, C. Burak, S.Z., Alpar, B., Türker, A. and Barut I.F. 2010 Foreseeable impacts of sea level rise on the southern coast of the Marmara Sea (Turkey), Water Policy 12 (6), 932-943

Gevaerta, A.I. Parinussab, R.M. Renzulloc, L.J. Dijkd, A.I.J.M. V., and Jeu. R.A.M. D. 2016. Spatio-temporal evaluation of resolution enhancement for passivemicrowave soil moisture and vegetation optical depth. International Journal of Applied Earth Observation and Geoinformation 45 (2016) 235-244.

Grady B. Wright 2003. Radial Basis Function Interpolation, Numerical and Analytical Developments. Imamoglu,M.Z., Sertel, E., Kurucu,Y., Örmeci, C., 2011. Mapping Of Different Soil Proporties By Means Of Geostatistical Methods and Analysis With GIS, II. Soil and Water Supply Congress, 2011, Ankara, Turkey.

Hejmenowska, B. And Mularz, S. 2000. Integration of multitemporal Ers Sar And Landsat TM data for soil moisture assesment, IAPRS, Vol, XXXIII, Amsterdam.

IPCC, 2013. Summary for Policymakers. In: Climate Change 2013: The Physical Science Basis. Contribution of Working Group I to the Fifth Assessment Report.

Jaroslaw Kaya Zawadzki, Mateusz K, edzior, 2016. Soil moisture variability over Odra watershed: Comparison betweenSMOS and GLDAS data. International Journal of Applied Earth Observation and Geoinformation 45 (2016) 110-124

Kaya., H. and Gazioğlu, C. 2015. Real Estate Development at Landslides, International Journal of Environment and Geoinformatics Vol:2(1), 62-71.

Laiolo, P., et al., 2015. Impact of different satellite soil moisture products on the predictions of a continuous distributed hydrological model. Int. J. Appl. EarthObserv. Geoinf.

Laurent L, Boucard P, Soulier B. 2013. Generation of a cokriging metamodel using a multiparametric strategy. Comput Mech 51: 151-169.

M.J.Smith, M.F.Goodchild, P.A.Longley, 2007, Geospatial Analysis: Comprehensive Guide to Principles, Techniques and Software Tools.

Matheron G. 1963. Principles of geostatistics. Econ Geol 58:1246-1266.

Musaoglu, N., Kaya, S., Seker, D. Z., \& Goksel, C. (2002). A case study of using Remote Sensing Data and GIS for Land Management, Catalca Region. FLG XXII International Congress USA, Washington D.C. USA, April 19-26, 2002.

Olea, R.A. 1982. Optimization of the High Plains Aquifer Observation Network, Kansas. Kansas Geological Survey, Grandwater Series, No. 7, Lawrence, Kansas.

Panegrossi, G., Ferretti, R., Pulvirenti, L., Pierdicca, N., 2011. Impact of ASAR soilmoisture data on the MM5 precipitation forecast for the Tanaro flood event ofApril 2009. Nat. Hazards Earth Syst. Sci. 11, 3135-3149.

Qiang Wang, Rogier van der Velde, Zhongbo $\mathrm{Su}$, Jun Wen 2016. Aquarius L-band scatterometer and radiometer observations over aTibetan Plateau site. International Journal of Applied Earth Observation and Geoinformation 45 (2016) 165-177

Şeker, D.Z., Direk, Ş., Musaoğlu, N. and Gazioğlu, C. 2013. Determination of Effects of Coastal Deformation Caused by Waves and Storms at Black Sea Coast of Turkey 
utilizing InSAR Technique, AGU Fall Meeting Abstracts, Vol. 1, 1629

Seneviratne, S.I., Corti, T., Davin, E.L., Hirschi, M., Jaeger, E.B., Lehner, I., Orlowsky,B., Teuling, A.J. 2010. Investigating soil moisture-climate interactions in achanging climate: a review. Earth-Sci. Rev. 99, 125-161.

Sertel E, Demirel H and Kaya Ş, 2012. Predictive Mapping Air Pollutantas: A Spatial Approach, Proceedings CD of the Fifth International Spatial Data Quality Symposium, ITC, CD Nm.17, Enschede, Netherland.

Sertel E, Kutoglu SH and Kaya Ş. 2007. Geometric correction accuracy of different satellite sensor images: application of figure condition. Int J Remote Sens 28(20):46854692. doi:10.1080/01431160701592452

Simav, Ö.; Şeker, D.Z. and Gazioğlu, C. 2013. Coastal inundation due to sea level rise and extreme sea state and its potential impacts: Çukurova delta case. Turk. J. Earth Sci., 22, 671-680.

Tobler, W. 1970. A Computer Movie Simulating Urban Growth in the Detroit Region. Economic Geography, 46(2): 234240.

URL 1: http://pro.arcgis.com/en/proapp/help/analysis/geostatisticalanalyst/how-global-polynomialinterpolation-works.htm.

Vieira, S.R., Hatfield, J.L., Nielsen, D.R., Biggar, J.W., 1983. Geoistatistical Theory and Application to Variabilitiy of Some Agronomical Properties, Hilgardia, 51, 3, 175.

Western, A.W. and Blöschl, G., 1999. On the spatial scaling of soil moisture, Journal of Hydrology, 217: 203-224.

Xiaoqing Z, Miao L, Shuying Z 2013. Spatial Interpolation of the Chlorophyll-a Concentration in Zhalong Wetland Based on Cokringing. Chin.Agric.Sci.Bull 29: 160-164. 